\title{
Positive Modulation of SK Channel Impedes Neuron-Specific Cytoskeletal Organization and Maturation
}

\author{
Amita Shrestha Razia Sultana Philip A. Adeniyi Charles C. Lee \\ Olalekan M. Ogundele \\ Department of Comparative Biomedical Sciences, Louisiana State University School of Veterinary Medicine, \\ Baton Rouge, LA, USA
}

\section{Keywords}

SK2/3 · Doublecortin · Neurofilament · Type III $\beta$-tubulin ·

Cortex $\cdot$ Hippocampus

\begin{abstract}
$\mathrm{N}$-methyl-D-aspartate receptor (NMDAR) modulates the structural plasticity of dendritic spines by impacting cytoskeletal organization and kinase signaling. In the developing nervous system, activation of NMDAR is pertinent for neuronal migration, neurite differentiation, and cellular organization. Given that small conductance potassium channels (SK2/3) repress NMDAR ionotropic signaling, this study highlights the impact of neonatal SK channel potentiation on adult cortical and hippocampal organization. Neonatal SK channel potentiation was performed by one injection of SK2/3 agonist (CyPPA) into the pallium of mice on postnatal day 2 (P2). When the animals reached adulthood (P55), the hippocampus and cortex were examined to assess neuronal maturation, lamination, and the distribution of synaptic cytoskeletal proteins. Immunodetection of neuronal markers in the brain of P2-treated P55 mice revealed the presence of immature neurons in the upper cortical layers (layers II-IV)
\end{abstract}

and CA1 (hippocampus). Also, layer-dependent cortical-cell density was attenuated due to the ectopic localization of mature $\left(\mathrm{NeuN}^{+}\right)$and immature (Doublecortin ${ }^{+}\left[\mathrm{DCX}^{+}\right]$) neurons in cortical layers II-IV. Similarly, the decreased count of $\mathrm{NeuN}^{+}$neurons in the CA1 is accompanied by an increase in the number of immature $D C X^{+}$neurons. Ectopic localization of neurons in the upper cortex and CA1 caused the dramatic expression of neuron-specific cytoskeletal proteins. In line with this, structural deformity of neuronal projections and the loss of postsynaptic densities suggests that postsynaptic integrity is compromised in the $\mathrm{SK} 2 / 3^{+}$brain. From these results, we deduced that SK channel activity in the developing brain likely impacts neuronal maturation through its effects on cytoskeletal formation.

(c) 2020 S. Karger AG, Basel

\section{Introduction}

Transient $\mathrm{Ca}^{++}$current generated by N-methyl-D-aspartate receptor (NMDAR)-GluN1 potentiation constitutes approximately $75 \%$ of postsynaptic $\mathrm{Ca}^{++}$that modulates synaptic plasticity [1-4]. By activating several syn- 
aptic downstream kinases, synaptic potentiation events are further coupled to cellular regulation and gene expression [5-11]. This process represents an ordered cue of signaling events that determines protein recruitment to synapses, cell death, synaptic potentiation or inhibition, and synaptic cytoskeletal organization $[9,10,12-$ 15]. In the developing nervous system, potentiation of NMDAR directs neuronal migration and cellular organization. Genetic ablation or pharmacological inhibition of NMDAR leads to erroneous migration patterns that alter neural organization [14, 16-20]. Likewise, the loss of NMDAR function during the critical periods of brain development results in perturbations of neural circuits and region-dependent cell density [17, 21-23]. Substantive evidence also exists to suggest that the ablation of NMDAR function in newly formed synapses can lead to defects in synaptic pruning, delayed maturation, and aberrant distribution of synapses [24-26]. Loss of NMDAR function and aberrant neuronal migration patterns are implicated in the etiology and progression of developmental neuropsychiatric disorders like autism $[21,24,25$, 27-33].

The regulation of long-term synaptic potentiation can offer significant insights into the concept of NMDAR hypofunction in developmental cognitive defects. NMDARmediated synaptic potentiation is dependent on the activation of kinases that facilitate high-frequency neuronal firing and rearrangement of the synaptic cytoskeleton. Accordingly, the synaptic potentiation rate and structure of the dendritic spine cytoskeleton underlie structural and functional plasticity of fully developed synapses $[2,3$, 31, 34-39].

SK2 is a small conductance channel that is localized with the NMDAR at postsynaptic densities (PSDs) [4049]. Because of the proximity to NMDAR, glutamatergic ionotropic neurotransmission produces most of the postsynaptic $\mathrm{Ca}^{++}$transients that activate SK channel $[44,46]$. SK channel is a homomeric tetramer that assembles poreforming subunits when $\mathrm{Ca}^{++}$binds to the calmodulin $(\mathrm{CaM})$ on the CaM lobe $[50,51]$. Activation of SK2 represents an ion channel-gating mechanism that promotes $\mathrm{K}^{+}$ after hyperpolarization currents which abrogate synaptic potentiation [42, 46-48, 52-54]. As a result, SK2 regulates "excitability" by enhancing "synaptic adaptation." Mechanistically, NMDAR-mediated dendritic spine plasticity is tuned by repetitive activation of SK channel mediated through transient $\mathrm{Ca}^{++}$currents. This leads to the suppression of synaptic plasticity [41-43, 50, 51, 55-59].

Activation of NMDAR in the developing brain is pertinent to cytoskeletal differentiation and maturation [60-
64]. Similar to plasticity in the adult brain, NMDAR signaling in the developing brain directs kinase activity that facilitates cytoskeletal assembly for dendrite branching, axon guidance, and neuronal migration [65-68]. Given that SK channel refines the activity of NMDAR in dendritic spines [49,56], there is a need to investigate the role of SK2 in the developmental organization of pallial neurons destined for the cortex and hippocampus.

Our results revealed that neonatal positive modulation of SK channel impedes maturation and cytoskeletal organization of pallial neurons in the adult cortex and hippocampus. Specifically, neonatal positive modulation of SK channel caused the ectopic localization of adult neurons and abnormal expression of cytoskeletal proteins in cortical layers II-IV and the hippocampal CA1/subiculum region. In addition to the aberrant distribution of neuron-specific cytoskeletal proteins, some of the ectopic neurons exhibited delayed maturation.

\section{Methods}

Animals

Adult male and female C57BL/6 mice were housed as mating pairs. Animals were housed under standard laboratory conditions of a 12-h alternating light/dark cycle with food and water provided ad libitum. All procedures performed in this study were approved by the Institutional Animal Care and Use Committee (IACUC) of the Louisiana State University School of Veterinary Medicine.

\section{Intracranial CyPPA Injection}

In a separate set of litters, CyPPA (Tocris \#2953) or saline was injected into the pallium on postnatal day 2 (P2). Pups were sedated with isoflurane, with the head and body held in position by rigid foam. A hydraulic, ultrafine micromanipulator (Narishige) was used to determine stereotaxic coordinates relative to the bregma. The coordinate for the medial pallium (AP: $-0.5 \mathrm{~mm}, \mathrm{ML}: 0.2$ $\mathrm{mm}, \mathrm{DV}: 1.0 \mathrm{~mm}$ ) were determined using the Allen Developing Mouse Brain Atlas. The micromanipulator probe holder, carrying a 32-gauge Hamilton syringe, was gently lowered to penetrate the skin and cranium. CyPPA (10 $\mu \mathrm{M}$; Tocris \#2953), prepared in cremophor glucose, was injected gradually at the rate of $2 \mu \mathrm{L} / \mathrm{min}$. A total volume of $2 \mu \mathrm{L}$ was injected per neonate. The injector was left in place for $5 \mathrm{~min}$ after the drug had been delivered. The treated animals $\left(\mathrm{SK} 2 / 3^{+}\right)$were returned to the maternal cage and monitored thereafter. Mice were weaned on P28 and housed based on sex.

\section{Western Blotting}

Frozen hippocampal tissue was incubated on ice with RIPA lysis buffer containing protease and phosphatase inhibitor cocktail. After $30 \mathrm{~min}$, the incubated tissue was rapidly homogenized to obtain whole-tissue lysate. $10 \mu \mathrm{g}$ of protein was processed for SDSPAGE electrophoresis. After Western blotting (wet transfer), a PVDF membrane was incubated in Tris-buffered saline (with $0.01 \%$ Tween 20 ) for $15 \mathrm{~min}$ (TBST) at room temperature. After-
60

Dev Neurosci 2020;42:59-71

DOI: $10.1159 / 000507989$ 
ward, the membrane was blocked in 3\% BSA (prepared in TBST) for $50 \mathrm{~min}$ at room temperature. The level of cytoskeletal proteins in the hippocampus was determined using rabbit anti-Doublecortin (DCX) antibody (Cell Signaling \#14802S), rabbit anti-Neurofilament antibody (Cell Signaling \#2837S), rabbit anti- $\beta$-tubulin (type III) (Cell Signaling \#5568S), and rabbit anti-PSD-95 (Cell Signaling \#3450) antibody at a dilution of 1:1,000. The membrane was incubated in the primary antibody solution overnight at $4{ }^{\circ} \mathrm{C}$. After two 10-min washes in TBST, the primary antibodies were detected using chicken anti-rabbit-HRP (Thermo Fisher Scientific \#A15987) at a dilution of 1:5,000. The reaction was developed using a chemiluminescence substrate (Thermo Fisher Scientific \#34579). To detect housekeeping protein, the membranes were treated with Restore PLUS Western blot stripping buffer (Thermo Fisher Scientific \#46430), and reprobed (overnight at $4{ }^{\circ} \mathrm{C}$ ) with HRP-conjugated GAPDH polyclonal antibody (Thermo Fisher Scientific \# PA1-987-HRP) prepared in blocking solution. Protein expression was normalized per lane using the corresponding GAPDH expression.

\section{Immunofluorescence}

Adult mice were transcardially perfused with $10 \mathrm{mM}$ PBS and then $4 \%$ phosphate-buffered paraformaldehyde (PB-PFA). The whole brain was removed and fixed in $4 \%$ PB-PFA overnight. Subsequently, the brain was transferred into $4 \%$ PB-PFA containing $30 \%$ sucrose for cryopreservation (for 36-72 h). Free-floating cryostat sections $(40 \mu \mathrm{m})$ were obtained and preserved in 48 -well plates containing $10 \mathrm{mM} \mathrm{PBS}$ at $4{ }^{\circ} \mathrm{C}$. The sections were washed 3 times (for $5 \mathrm{~min}$ each) in $10 \mathrm{mM}$ PBS ( $\mathrm{pH}$ 7.4) on a slow orbital shaker. Blocking of nonspecific protein interaction was performed in $5 \%$ normal goat serum (Vector Labs $\# S$ - 1000 ) prepared in 10 $\mathrm{mM}$ PBS $+0.03 \%$ Triton-X100 for $1 \mathrm{~h}$ at room temperature. The sections were incubated overnight at $4^{\circ} \mathrm{C}$ in the following primary antibodies; rabbit anti-NeuN Alexa-488 conjugate (EMD Millipore \#MAB377XM), rabbit anti-DCX antibody (Cell Signaling \#14802S), rabbit anti-Neurofilament antibody (Cell Signaling \#2837S), and rabbit anti- $\beta$-tubulin (type III) antibody (Cell Signaling \#5568S). The primary antibodies were diluted in blocking solution (10 mM PBS + 0.03\% Triton-X100 and 5\% normal goat serum). After primary antibody incubation, the sections were washed 2 times in $10 \mathrm{~mm}$ PBS, and then incubated in a secondary antibody, goat anti-rabbit Alexa 568 (Thermo Fisher Scientific \#A11036) diluted in the blocking solution. Secondary antibody incubation was done for $1 \mathrm{~h}$ at room temperature, with gentle shaking $(35 \mathrm{rpm})$. Immunolabeled sections were washed and mounted on gelatincoated slides using ProLong ${ }^{\mathrm{TM}}$ Diamond antifade mountant containing DAPI (Thermo Fisher Scientific \#P36971).

\section{Expansion Microscopy}

Cryostat-sectioned brain slices were incubated in rabbit antiNeurofilament primary antibody (Cell Signaling \# 2837) overnight at $4{ }^{\circ} \mathrm{C}$. After washing in the blocking buffer, sections were incubated in goat anti-rabbit Alexa 568 (Thermo Fisher Scientific \#A11036) secondary antibody diluted in $10 \mathrm{~mm}$ PBS + 0.03\% Triton-X100 and 5\% normal goat serum. Anchoring treatment was done overnight in $0.1 \mathrm{mg} / \mathrm{mL}$ Acryloyl-X. Gelation, overnight digestion, and mounting was performed using previously described methods $[69,70]$.

SK Channel Potentiation Impedes

Neonatal Neuronal Organization

\section{Quantification}

Images of fluorophore-labeled protein in brain sections were acquired through a Nikon-NiU fluorescence upright microscope capable of 3-D imaging. Z-stacks were obtained and converted into 2-D images through the "extended depth of focus (EDF)" option in the Nikon Element Advanced Research software. Normalized fluorescence intensity for immunolabeled proteins in the hippocampus and cortex were determined in optical slices for serial section images ( $n=4$ per group). Fluorescence intensity and cell count were determined using Image J software. Grids were positioned on images using the Grid2 plugin in Image J. We determined the mean fluorescence intensity per unit area using the distribution of the grids on anatomically defined cortical layers and regions of the hippocampus. The mean intensity in each grid was normalized as a percentage of the total mean intensities for all grids. Similarly, cell counting was performed to determine the distribution of cells per unit area (grid). In subsequent analysis, each grid was assigned to an anatomical layer (cortex) or region (hippocampus).

\section{Statistical Analysis}

Fluorescence intensity, cell count, and Western blot protein level for control and SK $2 / 3^{+}$group were compared by $t$ test analysis. Upper and lower cortical cell count or fluorescence intensity was also determined by $t$ test analysis across groups. Statistical comparison of $>2$ cortical layers or hippocampal region was performed in one-way ANOVA. All statistical analyses were carried out in GraphPad Prism v8.0. Here, we presented the results as point graphs with error bars depicting the mean and standard error of the mean (SEM), respectively.

\section{Results}

\section{Cortical and Hippocampal Distribution of Adult Neurons}

In the P55 brain, the distribution of adult neurons in the cortex was determined by $\mathrm{NeuN}^{+}$immunostaining (Fig. 1a). Our results showed that neonatal SK channel potentiation led to an increase in adult neuron cell count in the cortex. $\mathrm{NeuN}^{+}$cells increased significantly in the $\mathrm{SK} 2 / 3^{+}$cortical layer II/III when compared with the control $(p=0.005$; Fig. $1 b)$. Similarly, the SK $2 / 3^{+}$cortical layer IV recorded an increase in $\mathrm{NeuN}^{+}$cell count when compared with the control ( $p<0.0001$; Fig. 1c). No significant difference was observed for SK2 $/ 3^{+}$cortical layers $\mathrm{V}-\mathrm{VI} \mathrm{NeuN}^{+}$cell count when compared with the control ( $p=0.3902$; Fig. 1d). Subsequent comparison of layerdependent $\mathrm{NeuN}^{+}$cell count showed that layer II/III cell count was higher than that of layer IV in the control cortex $(p<0.0001$; Fig. 1e). The same was the case for the $\mathrm{SK} 2 / 3^{+}$cortex, but the level of significance was lower $(p=$ 0.0002; Fig. 1f). In support of this outcome, a comparison of $\mathrm{NeuN}^{+}$cell count for control cortical layers IV and VVI showed no significant difference ( $p=0.10$; Fig. 1e). 


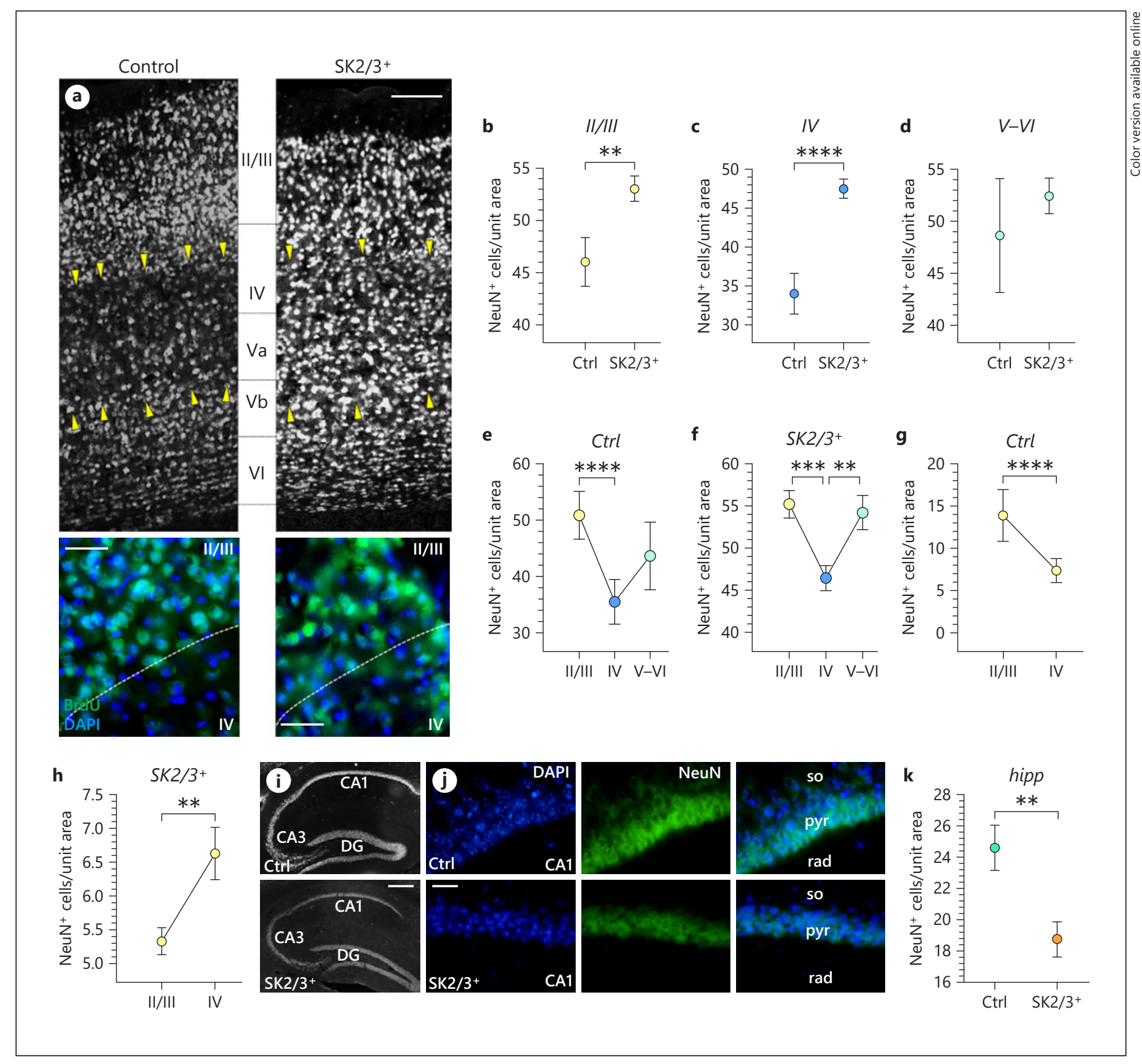

Fig. 1. Adult neuron count in the cortex and hippocampus of control and $\mathrm{SK} 2 / 3^{+}$mice (P55). a Low-magnification fluorescence images demonstrating the distribution of adult neurons $\left(\mathrm{NeuN}^{+}\right)$in the cortex of control and SK $2 / 3^{+}$mice. Scale bar, $50 \mu \mathrm{m}$ and $25 \mu \mathrm{m}$. b Graph showing increased $\mathrm{NeuN}^{+}$cell count in layer II/III of the SK2 $/ 3^{+}$cortex. ${ }^{* *} p=0.005$. c Graph showing increased $\mathrm{NeuN}^{+}$cell count in layer IV of the SK $2 / 3^{+}$cortex. ${ }^{* * * *} p<0.0001$. d Graph illustrating the comparative count of $\mathrm{NeuN}^{+}$cell in cortical layers V-VI (ns; $p=0.3902)$. Graphical representation of $\mathrm{NeuN}^{+}$cell distribution for the layers of the control $\left(\mathbf{e},{ }^{* * * *} p<0.0001\right)$ and
SK $2 / 3^{+}$cortex $\left(\mathbf{f},{ }^{* * *} p=0.0002,{ }^{* *} p=0.0033\right)$. Graphs demonstrate $\mathrm{NeuN}^{+}$cell count for border region between layer II/III and layer IV. g Control: layer II/III count is higher than layer IV. $* * * * p<0.0001$. h SK2 $/ 3^{+}$: layer IV count is higher than layer II/III. $* * p=0.0014$. $\mathbf{i}$, j Low-magnification (scale bar, $100 \mu \mathrm{m}$ ) and highmagnification (scale bar, $25 \mu \mathrm{m}$ ) fluorescence images demonstrating the distribution of $\mathrm{NeuN}^{+}$cells in the hippocampus. so, stratum oriens; pyr, pyramidal cell layer; rad, stratum radiatum. k Graph demonstrating a reduction in CA1 $\mathrm{NeuN}^{+}$cell count in the SK $2 / 3^{+}$hippocampus (hipp). ${ }^{* *} p=0.0036$. 

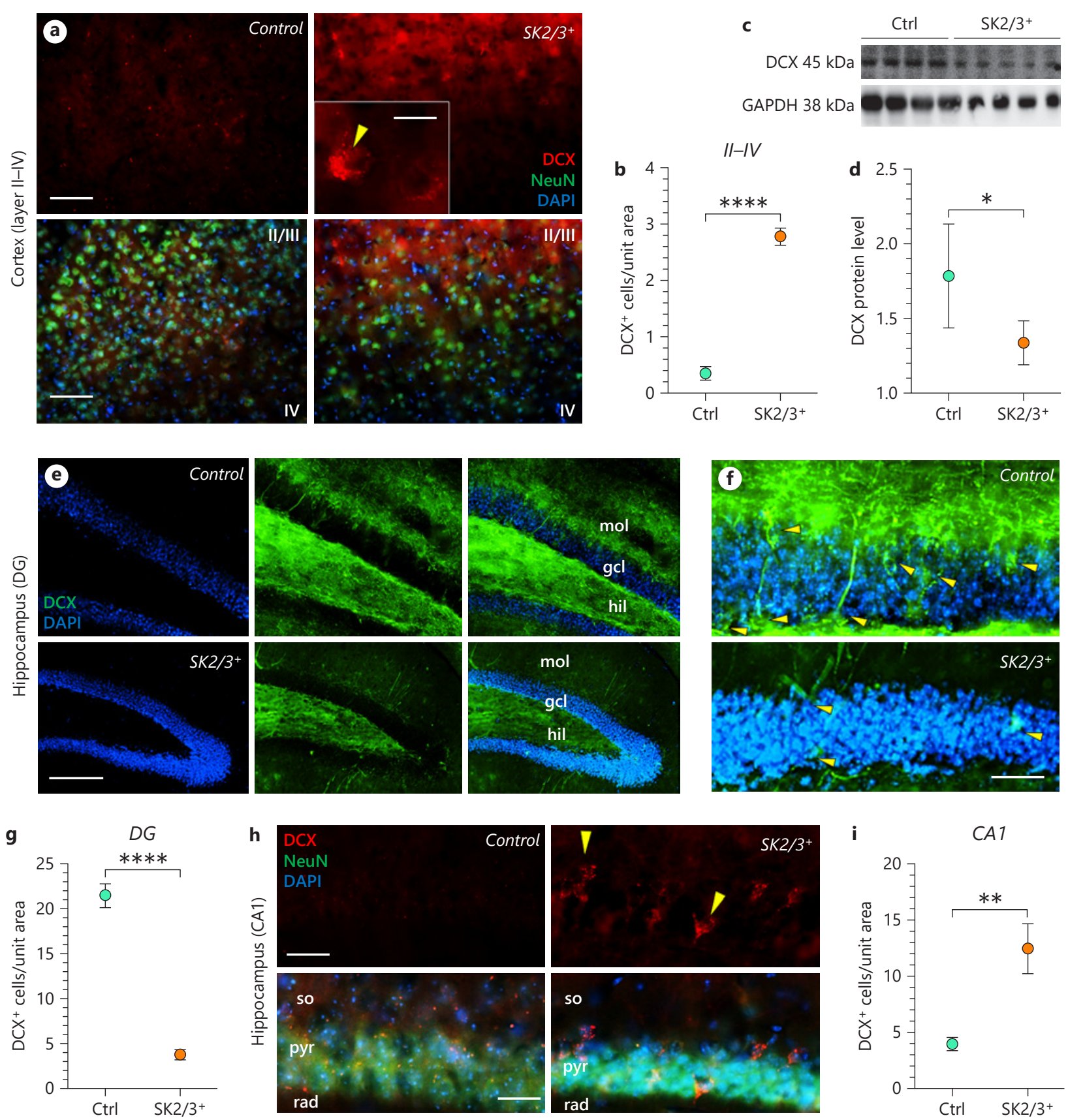

Fig. 2. Distribution of $\mathrm{DCX}^{+}$cells in the cortex and hippocampus of adult mice (P55) treated in early neonatal development. a Representative fluorescence images demonstrating the expression of DCX in the cortex. Scale bar, $40 \mu \mathrm{m}$ and $10 \mu \mathrm{m}$. b Graph demonstrating higher $\mathrm{DCX}^{+}$cell count in the SK $2 / 3^{+}$cortical layer II/III. **** $p<0.0001$. c Western blot detection of DCX level in whole hippocampal lysate. This demonstrates the DCX loss in the SK2/3 ${ }^{+}$ hippocampus (see also Fig. 3e). d Graph showing a lower DCX level in the SK $2 / 3^{+}$hippocampus. ${ }^{*} p=0.0147$. e Representative fluorescence images demonstrating the expression of DCX in the DG. Scale bar, $20 \mu \mathrm{m}$. mol, molecular layer; gcl, granule-cell layer; hil, hilus. $\mathbf{f}$ Higher-magnification images of $\mathrm{DCX}^{+}$neurons (yellow arrowheads) in the DG. $\mathbf{g}$ Graph showing a decrease in $\mathrm{DCX}^{+}$neuron count per unit area of the SK2 $/ 3^{+}$DG. ${ }^{* * * *} p<0.0001$. h Immunofluorescence labeling of DCX in the CA1. so, stratum oriens; pyr, pyramidal cell layer; rad, stratum radiatum. Scale bar, $20 \mu \mathrm{m}$. i Graph demonstrating an increase in $\mathrm{DCX}^{+}$cell count in the CA1 of SK $2 / 3^{+}$hippocampus. ${ }^{* *} p=0.01$. 
However, in the SK2 $/ 3^{+}$cortex, the layer IV NeuN ${ }^{+}$cell count was significantly lower than that of layers V-VI ( $p=0.0033$; Fig. 1f).

Together, these results demonstrate an increase in upper cortical (layer II-IV) $\mathrm{NeuN}^{+}$count for the SK $2 / 3^{+}$cortex and are supported by the loss of layer-dependent cell density (yellow arrows; Fig. 1a). To detect ectopic distribution in cortical layer IV, we analyzed high-magnification images showing the lower region of layer II/III and the upper part of layer IV (Fig. 1a; lower panel). As expected, the control recorded a significantly higher cell count for layer II/III than for layer IV (Fig. 1g; $p<0.0001$ ). Conversely, the $\mathrm{NeuN}^{+}$cell count was significantly higher in the SK $2 / 3^{+}$cortical layer IV than that of layer II/III $\left(p=0.0014\right.$; Fig. 1h). Analysis of $\mathrm{NeuN}^{+}$cell distribution in the hippocampus revealed a change in cell count in parts of the hippocampus (Fig. 1i). Notably, there was a significant decrease in $\mathrm{CA} 1 \mathrm{NeuN}^{+}$count in the SK2/3 $3^{+}$ hippocampus (Fig. 1j, k; $p=0.0036$ ) when compared with the control.

\section{DCX and Delayed Maturation}

Immunofluorescence detection of DCX demonstrates the ectopic localization of immature neurons in the SK $2 / 3^{+}$upper cortical layers on P55 (Fig. 2a). Clusters of $\mathrm{DCX}^{+}$neurons were found in the SK2 $/ 3^{+}$cortex but not in the control (yellow arrowhead). Colocalization of DCX and adult neuron $\left(\mathrm{NeuN}^{+}\right)$suggests that immature neurons were ectopic in the upper layers (II-IV) of the SK2 $/ 3^{+}$ cortex and absent in the control cortex (Fig. 2b; $p<$ 0.0001).

Immunoblot analysis of DCX (Fig. 2c) revealed a decrease in hippocampal protein expression for the SK2 $/ 3^{+}$ group (Fig. $2 c-d ; p=0.0147$ ). This was made further evident by a decrease in DCX immunofluorescence and cell count in the dentate gyrus (DG) of SK $2 / 3^{+}$mice (Fig. 2ef). Compared with the control, the $\mathrm{SK} 2 / 3^{+}$group recorded a lower DCX ${ }^{+}$cell count in the DG (Fig. 2g; $p<0.0001$ ). Interestingly, there was a significant increase in the count of $\mathrm{DCX}^{+}$neurons in the CA1 of SK2/3 ${ }^{+}$mice (Fig. $2 \mathrm{~h}$ ). This result demonstrates ectopic localization of immature neurons (Fig. $2 \mathrm{i} ; p=0.01$ ) and supports the observed decrease in mature $\left(\mathrm{NeuN}^{+}\right)$neuron cell count in the CA1.

\section{Neonatal SK Channel Potentiation Abrogates \\ Cytoskeletal Maturation \\ Neurofilament}

The distribution of neurofilament in the layers of the cortex further supports the results for SK2 $/ 3^{+}$-induced aberrant neuron distribution and cytoskeletal maturation (Fig. 3a). The expression of neurofilament was higher in the control upper cortical layers (II-IV) than in the lower cortex (V-VI) (Fig. 3b; $p=0.045)$. While this was the case in the SK2 $/ 3^{+}$brain, the upper cortex exhibited overexpression of neurofilament and may indicate abnormal neural projections in this brain area. To this effect, a comparison of layer II-IV with layer V-VI neurofilament expression in the SK2 $/ 3^{+}$cortex produced a higher level of significance (Fig. 3c; $p<0.0001$ ). Similarly, normalized fluorescence intensity for neurofilament in the SK2 $/ 3^{+}$ upper cortex was empirically higher than in the control (Fig. 3d; $p=0.27$ ). Comparatively, in the lower cortical region (layers V-VI), fluorescence detection decreased in the SK $2 / 3^{+}$brain (Fig. 3e; $p=0.026$ ).

Aberrant distribution of neurofilament was also recorded in the SK2 $/ 3^{+}$hippocampus (Fig. 3f). There was no significant difference in neurofilament expression for control CA1, CA3, DG, and subiculum (Fig. 3g). In contrast, the SK2 $/ 3^{+}$subiculum (Fig. $3 \mathrm{~h}$ ) recorded significantly higher neurofilament level when compared with the CA1 $(p<0.0001)$, CA3 $(p=0.005)$, and DG ( $p=$ $0.0005)$. In support of this outcome, Immunoblot analysis of whole-hippocampal lysate revealed a significant loss of neurofilament in the SK2 $/ 3^{+}$hippocampus (Fig. 3i, j; $p=$ $0.0035)$. In comparison with the control, the SK $2 / 3^{+}$hippocampus showed a prominent loss of CA1 neurofilament (Fig. 3k, l; $p=0.0016$ ). Conversely, the subiculum was characterized by an overexpression of neurofilament (Fig. $3 \mathrm{~m} ; p=0.0041$ ). In addition to the CA1, neurofilament expression decreased significantly in the CA3 (Fig. 3n; $p=0.027$ ) and DG (Fig. 3o; $p=0.017$ ) regions of the $\mathrm{SK} 2 / 3^{+}$hippocampus.

\section{Type III $\beta$-Tubulin}

Dramatic distribution of type III $\beta$-tubulin in the SK $2 / 3^{+}$cortex supports the presence of aberrant neuronal projections (Fig. 4a). The SK $2 / 3^{+}$upper cortex (layers IIIV) recorded an overexpression of type III $\beta$-tubulin because of heavily labeled layer-IV neuronal cell bodies, and their projections to layer II/III (Fig. 4b; white arrowheads). In the control cortex, expression of type III $\beta$-tubulin in layers II-IV was higher than in layers V-VI $(p=0.0268$; Fig. 4c). Overexpression of type III $\beta$-tubulin in the SK $2 / 3^{+}$upper cortex was evident as a higher level of significance when layers II-IV expression was compared with that of layers V-VI ( $p<0.0001$; Fig. 4d). As illustrated in Fig. 4a, b, normalized fluorescence expression of type III $\beta$-tubulin was significantly higher in SK $2 / 3^{+}$layers II-IV than in the control $(p<0.0001$; 

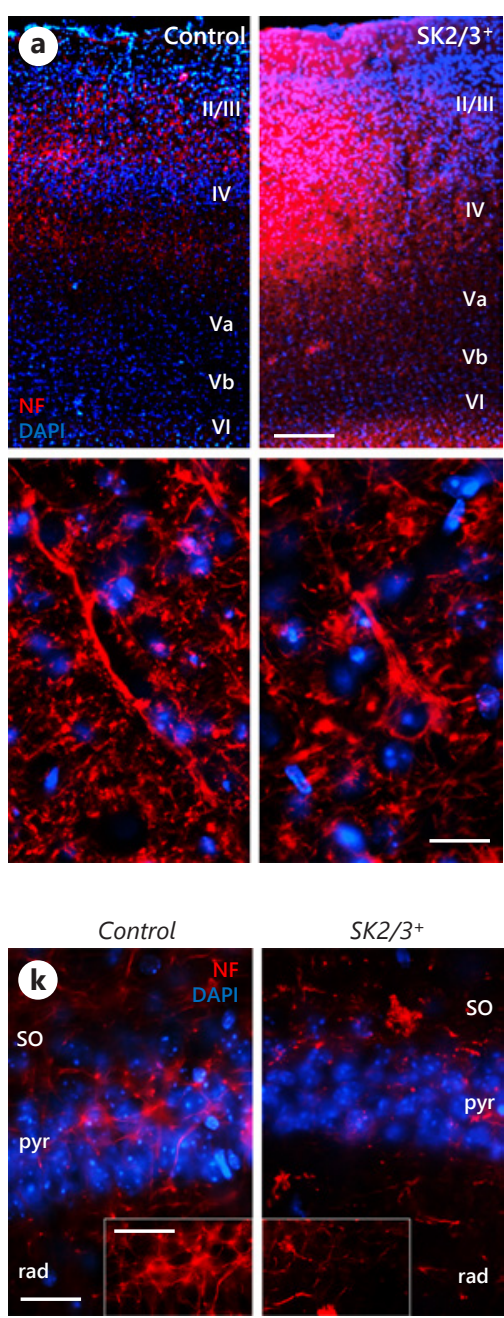
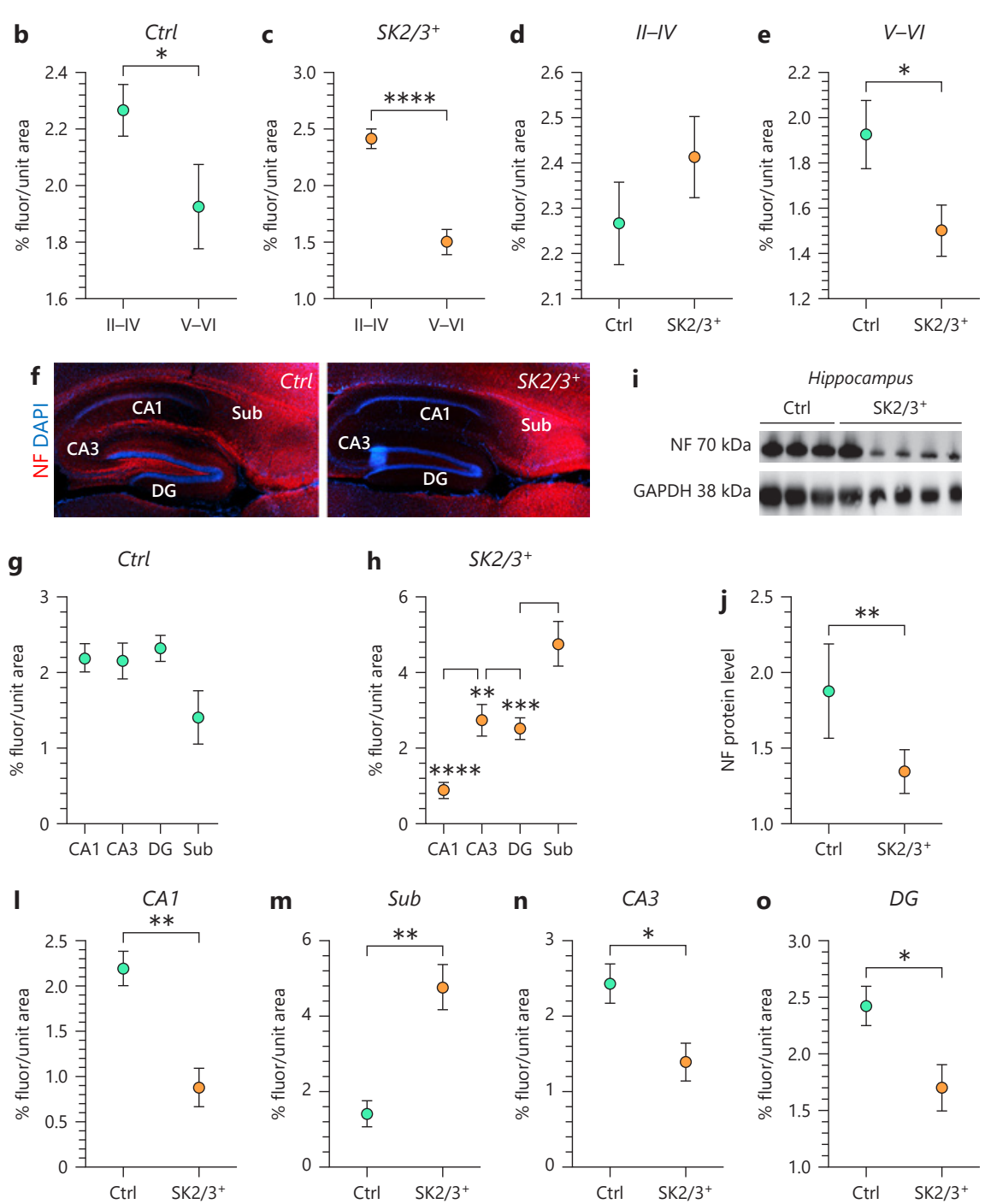

Fig. 3. Aberrant expression of neurofilament (NF) in the cortex and hippocampus of SK2/3+ mice. a Representative fluorescence images demonstrating NF expression in control and SK2 $/ 3^{+}$cortical layers. Scale bar, $100 \mu \mathrm{m}$ and $10 \mu \mathrm{m}$. b, c Graphical illustration of NF expression across cortical layers. Layer II-IV expression is higher than layer V-VI for both the control $(* p=0.045)$ and SK $2 / 3^{+}$cortex. ${ }^{* * * *} p<0.0001$. d Percentage fluorescence intensity per unit area (normalized) is not significantly different for the SK $2 / 3^{+}$layer II-IV when compared with the control $(p=0.27)$. e Graph showing a decreased normalized fluorescence intensity in the SK $2 / 3^{+}$layer V-VI. ${ }^{*} p=0.026$. f Fluorescence images showing the relative distribution of NF in control SK2/3 $/ 3^{+}$layer hippocampus (CA1, CA3, DG, and subiculum [Sub]). Scale bar, $100 \mu \mathrm{m}$.

g, h Graphs showing normalized NF expression in the CA1, CA3, and DG of control and SK2 $/ 3^{+}$hippocampus. $* * * * ~ p<0.0001$; ** $p=0.005$; ${ }^{* * *} p=0.0005$. $\mathbf{i}, \mathbf{j}$ Western blot and graph demonstrating a significant loss of $\mathrm{NF}$ in $\mathrm{SK} 2 / 3^{+}$whole hippocampal lysate $(p=0.0035)$. $\mathbf{k}$ Representative high-magnification image demonstrating loss of NF in the SK $2 / 3^{+}$hippocampal CA 1 region. $\mathrm{SO}$, stratum oriens; pyr, pyramidal cell layer; rad, stratum radiatum. Scale bar, $20 \mu \mathrm{m}$. I Graph illustrating decreased CA1 NF for the $\mathrm{SK} 2 / 3^{+}$group. ${ }^{* *} p=0.0016 . \mathrm{m}$ Graph illustrating increased NF in the SK $2 / 3^{+}$subiculum. ${ }^{* *} p=0.0041$. $\mathbf{n}-\mathbf{o}$ Graphs illustrating a significant loss of NF in the CA3 $(* p=0.027)$ and DG $(* p=0.017)$ of SK $2 / 3^{+}$hippocampus. 


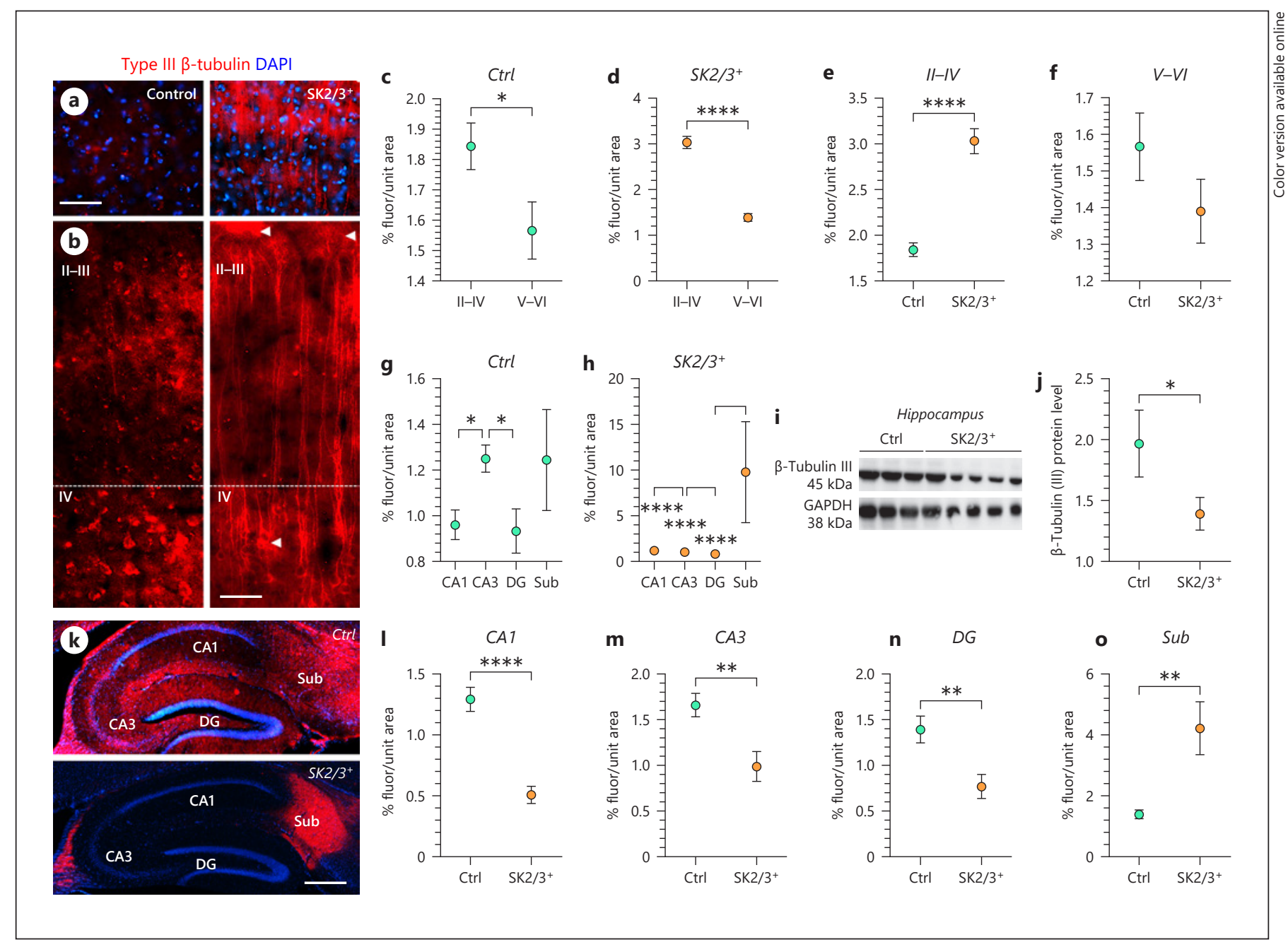

Fig. 4. Distribution of type III $\beta$-tubulin in the cortex and hippocampus. a Fluorescence images showing the expression of $\beta$-tubulin (III) in the cortex. scale bar, $50 \mu \mathrm{m}$. b Representative fluorescence images demonstrating layer IV projections to layer II/ III. Scale bar, $20 \mu \mathrm{m}$. c, d Graphs illustrating higher $\beta$-tubulin (III) expression in cortical layer II/III versus layer IV in control $(* p=$ $0.0268)$ and SK $2 / 3^{+}$cortex $(* * * * p<0.0001)$. e Graph illustrating increased $\beta$-tubulin (III) expression in SK $2 / 3^{+}$cortical layer II-IV. **** $p<0.0001$. f Graph comparing $\beta$-tubulin (III) expression in control and SK $2 / 3^{+}$cortical layer V-VI $(p=0.1675)$. g Graph illustrating the expression of $\beta$-tubulin (III) in control CA1, CA3,

Fig. 4e). Compared with the control, expression of type III $\beta$-tubulin did not significantly change in SK2 $/ 3^{+}$cortical layers V-VI (Fig. 4f; $p=0.01675$ ).

Regional expression of type III $\beta$-tubulin was also altered in the hippocampus of mice following neonatal $\mathrm{SK} 2 / 3^{+}$potentiation. In control mice, the CA3 and subiculum areas showed elevated type III $\beta$-tubulin expression. The CA1 $(p=0.022)$ and DG $(p=0.016$; Fig. $4 \mathrm{~g})$
DG, and subiculum (CA3 vs. CA1, ${ }^{*} p=0.022$; CA3 vs. DG, ${ }^{*} p=$ $0.0166)$. $\mathbf{h}$ Graph showing overexpression of $\beta$-tubulin (III) in the SK2/3 subiculum. ${ }^{* * * *} p<0.0001 . \mathbf{i}, \mathbf{j}$ Western blot and graph demonstrating a decrease in $\beta$-tubulin (III) expression for the SK2 $/ 3^{+}$ hippocampus. ${ }^{*} p=0.0434$. $\mathbf{k}$ Low-magnification images showing $\beta$-tubulin (III) expression in the hippocampus. Scale bar, $100 \mu \mathrm{m}$. I-n Graph demonstrating decreased $\beta$-tubulin (III) expression in the SK $2 / 3^{+}$CA1 (**** $\left.p<0.0001\right)$, CA3 (** $\left.p=0.0016\right)$, and DG (** $p=0.0021$ ). (o) Graph demonstrating overexpression of $\beta$-tubulin (III) in the SK2 $/ 3^{+}$subiculum, ${ }^{* *} p=0.0064$.

recorded lower type III $\beta$-tubulin level than in the control CA3. Conversely, the SK $2 / 3^{+}$hippocampus was characterized by an overexpression of type III $\beta$-tubulin in the subiculum $(p<0.0001)$ and a decrease in the CA1, CA3, and DG (Fig. 4h). The reduction in the total type III $\beta$-tubulin level in the SK2 $/ 3^{+}$hippocampus was further evident in Immunoblot detection of the protein in wholetissue lysates (Fig. 4i). A comparison of a normalized type 


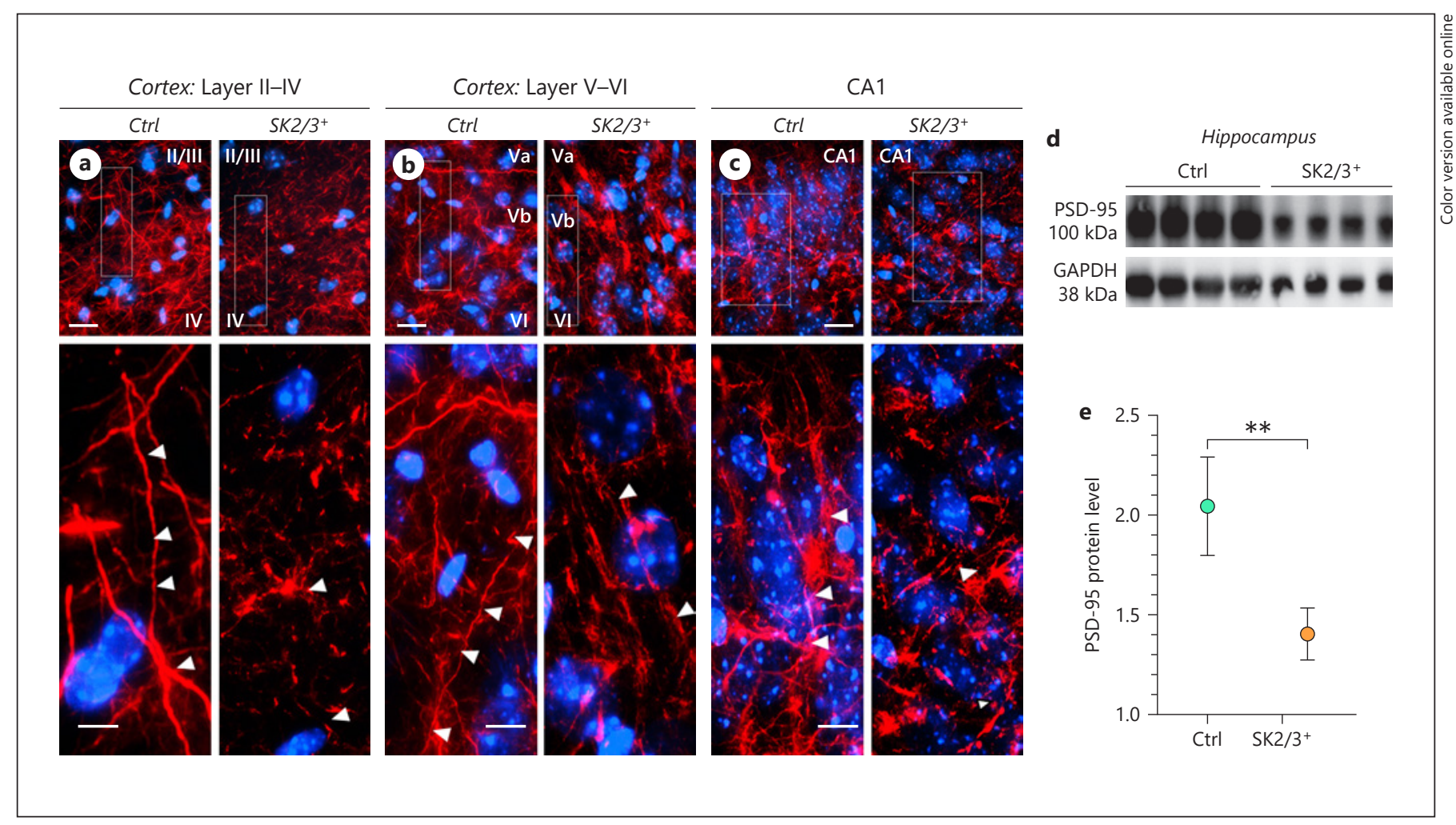

Fig. 5. Disruption of NF and PSD-95 in SK2/3 ${ }^{+}$brains. a-c Fluorescence images (ExM) illustrating fragmentation of $\mathrm{NF}$ in the SK2 $/ 3^{+}$cortex and hippocampus. Scale bar, $20 \mu \mathrm{m}$ and $\left.2 \mu \mathrm{m}\right)$. d, e Western blot and graph demonstrating a reduction in PSD-95 in the SK2/3+ hippocampus. ${ }^{* *} p=0.0016$.

III $\beta$-tubulin level in SK2 $/ 3^{+}$and control whole-hippocampal lysate revealed a significant decrease in the SK $2 / 3^{+}$ hippocampus (Fig. 4 ; $p=0.0434$ ). In support of this outcome, the comparison of normalized type III $\beta$-tubulin fluorescence for the control and SK2/3+ hippocampus (Fig. 4k-o) demonstrated a prominent loss in the SK2/3 $3^{+}$ CA1 $(p<0.0001), \mathrm{CA} 3(p=0.0016), \mathrm{DG}(p=0.0021)$, and overexpression in the subiculum $(p=0.0064)$.

\section{Structural Abnormalities in the Hippocampus and Cortex}

Ectopic localization of neurons in cortical layers II-IV (Fig. 1a, c) was accompanied by an increase in neuronspecific cytoskeletal protein distribution in the upper cortex and CA1 subiculum area (Fig. 3, 4). To examine the structure of neuronal processes (dendrites), we performed tissue expansion on brain slices following neurofilament immunolabeling. At a high magnification, our results showed normal neurofilament distribution in labeled neuronal processes in layers II-IV (Fig. 5a) and VVI (Fig. 5b) of the control cortex. In the SK $2 / 3^{+}$brain, there were aggregations of neurofilament (white arrow-

SK Channel Potentiation Impedes

Neonatal Neuronal Organization heads) which supports a possibility for cytoskeletal defects in the ectopic neurons previously identified in this area (Fig. 1a, Fig. 2a). Similarly, in the hippocampus (Fig. 5c), neurofilament aggregates were also observed in the pyramidal cell layer of the SK $2 / 3^{+} \mathrm{CA} 1$. In support of this result, Immunoblot analysis of whole-hippocampal lysate revealed a significant loss of postsynaptic protein marker (PSD-95) in the SK2 $/ 3^{+}$hippocampus (Fig. $5 \mathrm{~d}$, e) when compared with the control $(p=0.0016)$.

\section{Discussion}

In this study, we showed that neonatal SK channel potentiation significantly impeded cortical and hippocampal organization and cytoskeletal maturation. Notable changes in adult neuron distribution were associated with the loss of layer-dependent cell density in the cortex. To this effect, an increased layer IV neuron count was recorded on P55 for mice treated during early neonatal development (on P2). In support of this outcome, the distribution of neuron-specific cytoskeletal proteins in- 
creased significantly in the upper cortical layers II-IV, and in parts of the hippocampus (CA1 subiculum) where the ectopic cells are located. Interestingly, some of the ectopic neurons showed distinct characteristics of immature neurons with the absence of identifiable dendritic projections and DCX expression. Ultimately, there was evidence of postsynaptic cytoskeletal (neurofilament/ PSD-95) aberration in the cortex and hippocampus of adult mice following a neonatal SK channel potentiation.

The modification of synaptic structure and composition is characteristic of developmental neuropsychiatric disorders. In the etiology and progression of developmental cognitive defects, notable alterations in neural circuit organization and dendrite morphology have been identified. Specifically, in autism, erroneous regulation of neuronal migration leads to mistargeting of intracortical and subcortical neural projections [27, 71-75]. Furthermore, genetic mutations linked with autism have been shown to cause significant perturbations in spine morphology [76, 77].

Regulated expression and activity of NMDAR are essential for the development and organization of the nervous system. NMDAR signaling directs neuronal migration, synaptogenesis, synaptic pruning, and maturation $[26,30,60,61,63,64,68,78]$. For these processes, ionotropic and kinase signaling of NMDAR are pertinent for neurite formation and reorganization of the cytoskeleton during neuronal migration. As such, the ablation of NMDAR function in the developing nervous system causes an erroneous neural migration pattern and abolishes layerdependent neuron density in the cortex $[63,68]$. Although SK channel potentiation attenuates NMDAR activity, how SK channel potentiation impacts neuronal development and cytoskeletal organization is yet to be investigated.

SK channels are calcium-activated potassium channels that are colocalized with NMDAR at postsynaptic densities. Although it is found in every part of the brain, the expression of SK channels is relatively high in the hippocampal and cortical dendrites [41-44, 79, 80]. Previous studies established the role of SK in synaptic plasticity and memory encoding $[43,47]$. Accordingly, increased potentiation of SK channels ablates postsynaptic calcium transient towards inhibiting synaptic plasticity. Consistent with its effect on calcium signaling, persistent activation of SK channels depresses synaptic function and learning in mice $[42,81]$. Given that NMDAR signaling is required for structural plasticity of dendritic spines, and SK modulates NMDAR $\mathrm{Ca}^{++}$transient, it is likely that neonatal SK activity directs the aspects of neuronal maturation and cytoskeletal differentiation.
In normal brain function, modulation of NMDAR alters the structure of the spine cytoskeleton in an activitydependent manner. This process underlies memory encoding and long-term plasticity $[38,82-84]$. To this effect, changes in the shape and size of dendritic spines are directly related to the level of activity of the synapses. Dendritic spine dysgenesis has been identified in neuropsychiatric and neurodegenerative disorders which include autism, schizophrenia, Rhett's syndrome, Alzheimer's disease, and Down syndromes, among others $[76,77]$. Aberrations in dendritic spine morphology have been strongly linked to the dysregulation of NMDAR signaling at glutamatergic synapses that are localized on these spines $[17,83,85-88]$. In developing neurons, the organization of various proteins that constitute the neuronal cytoskeleton leads to neurite budding and differentiation. Disruption of cytoskeletal proteins during development significantly impacts neuronal migration and differentiation. As neurons mature, the transformation of cytoskeletal composition occurs and can be used to distinguish proliferating from fully formed neurons [89].

\section{Conclusion}

Our results showed that neonatal SK channel potentiation significantly impacts neuronal cytoskeletal organization and maturation. Notably, the cortex and hippocampus of neonatal CyPPA treated mice exhibits aberrant distribution of adult neurons and neuron-specific cytoskeletal proteins.

\section{Statement of Ethics}

All animal-handling procedures were approved by the Institutional Animal Care and Use Committee of the Louisiana State University School of Veterinary Medicine.

\section{Disclosure Statement}

The authors state that the present manuscript presents no conflict of interest.

\section{Funding Sources}

This study was supported by CBS bridging grants awarded to O.M.O. and an NIH grant (R03 MH 104851) to C.C.L. 


\section{Author Contributions}

O.M.O. and A.S. designed the experiments. O.M.O., A.S., R.S., and P.A.A. performed the experiments. All authors analyzed the results and prepared the manuscript. O.M.O. and C.C.L. conducted the final revision of the manuscript.

\section{Availability of Data and Materials}

The datasets used and/or analyzed in this study are available from the last author on reasonable request.

\section{References}

1 Bhat RV, Andersson U, Andersson S, Knerr L, Bauer U, Sundgren-Andersson AK. The Conundrum of GSK3 Inhibitors: Is it the Dawn of a New Beginning? J Alzheimers Dis. 2018; 64 s1:S547-54.

2 Coultrap SJ, Bayer KU. CaMKII regulation in information processing and storage. Trends Neurosci. 2012 Oct;35(10):607-18.

3 Hell JW. CaMKII: claiming center stage in postsynaptic function and organization. Neuron. 2014 Jan;81(2):249-65.

4 Lisman J, Yasuda R, Raghavachari S. Mechanisms of CaMKII action in long-term potentiation. Nat Rev Neurosci. 2012 Feb;13(3): 169-82.

5 Aow J, Dore K, Malinow R. Conformational signaling required for synaptic plasticity by the NMDA receptor complex. Proc Natl Acad Sci USA. 2015 Nov;112(47):14711-6.

6 Sanderson JL, Gorski JA, Dell'Acqua ML. NMDA Receptor-Dependent LTD Requires Transient Synaptic Incorporation of $\mathrm{Ca}^{2+}$ Permeable AMPARs Mediated by AKAP150Anchored PKA and Calcineurin. Neuron. 2016 Mar;89(5):1000-15.

7 Sanderson JL, Scott JD, Dell'Acqua ML. Control of Homeostatic Synaptic Plasticity by AKAP-Anchored Kinase and Phosphatase Regulation of Ca2+-Permeable AMPA Receptors. J Neurosci. 2018 Mar;38(11):286376.

8 Stein IS, Gray JA, Zito K. Non-Ionotropic NMDA Receptor Signaling Drives ActivityInduced Dendritic Spine Shrinkage. J Neurosci. 2015 Sep;35(35):12303-8.

9 Wang J, Lu W, Chen L, Zhang P, Qian T, Cao W, et al. Serine 707 of APPL1 is Critical for the Synaptic NMDA Receptor-Mediated Akt Phosphorylation Signaling Pathway. Neurosci Bull. 2016 Aug;32(4):323-30.

10 Waxman EA, Lynch DR. N-methyl-D-aspartate receptor subtype mediated bidirectional control of p38 mitogen-activated protein kinase. J Biol Chem. 2005 Aug;280(32):2932233.

11 Yoshii A, Constantine-Paton M. BDNF induces transport of PSD-95 to dendrites through PI3K-AKT signaling after NMDA receptor activation. Nat Neurosci. 2007 Jun; 10(6):702-11.

12 Hamodi AS, Liu Z, Pratt KG. An NMDA receptor-dependent mechanism for subcellular segregation of sensory inputs in the tadpole optic tectum. eLife. 2016 Nov;5:5.
13 Simões AP, Silva CG, Marques JM, Pochmann D, Porciúncula LO, Ferreira $S$, et al. Glutamate-induced and NMDA receptormediated neurodegeneration entails P2Y1 receptor activation. Cell Death Dis. 2018 Feb; 9(3):297.

14 Stroebel D, Casado M, Paoletti P. Triheteromeric NMDA receptors: from structure to synaptic physiology. Curr Opin Physiol. 2018 Apr;2:1-12.

15 Yan JZ, Xu Z, Ren SQ, Hu B, Yao W, Wang $\mathrm{SH}$, et al. Protein kinase $\mathrm{C}$ promotes $\mathrm{N}$-methyl-D-aspartate (NMDA) receptor trafficking by indirectly triggering calcium/calmodulindependent protein kinase II (CaMKII) autophosphorylation. J Biol Chem. 2011 Jul; 286(28):25187-200.

16 Aida T, Ito Y, Takahashi YK, Tanaka K. Overstimulation of NMDA receptors impairs early brain development in vivo. PLoS One. 2012; 7(5):e36853.

17 Bustos FJ, Jury N, Martinez P, Ampuero E, Campos M, Abarzúa S, et al. NMDA receptor subunit composition controls dendritogenesis of hippocampal neurons through CAMKII, CREB-P, and H3K27ac. J Cell Physiol. 2017 Dec;232(12):3677-92.

18 Fedder KN, Sabo SL. On the Role of Glutamate in Presynaptic Development: Possible Contributions of Presynaptic NMDA Receptors. Biomolecules. 2015 Dec;5(4):3448-66.

19 Gu X, Zhou L, Lu W. An NMDA ReceptorDependent Mechanism Underlies Inhibitory Synapse Development. Cell Rep. 2016 Jan; 14(3):471-8.

20 Wesseling $\mathrm{H}$, Guest PC, Lee CM, Wong EH, Rahmoune $\mathrm{H}$, Bahn S. Integrative proteomic analysis of the NMDA NR1 knockdown mouse model reveals effects on central and peripheral pathways associated with schizophrenia and autism spectrum disorders. Mol Autism. 2014 Jul;5(1):38.

21 Duffney LJ, Wei J, Cheng J, Liu W, Smith KR, Kittler JT, et al. Shank3 deficiency induces NMDA receptor hypofunction via an actindependent mechanism. J Neurosci. 2013 Oct; 33(40):15767-78.

22 Snyder MA, Gao WJ. NMDA hypofunction as a convergence point for progression and symptoms of schizophrenia. Front Cell Neurosci. 2013 Mar;7:31.

23 Wollmuth LP. Ion permeation in ionotropic glutamate receptors: still dynamic after all these years. Curr Opin Physiol. 2018 Apr;2: 36-41.
24 Sachana M, Rolaki A, Bal-Price A. Development of the Adverse Outcome Pathway (AOP): chronic binding of antagonist to $\mathrm{N}$ methyl-d-aspartate receptors (NMDARs) during brain development induces impairment of learning and memory abilities of children. Toxicol Appl Pharmacol. 2018 Sep;354: 153-75.

25 Ohgi Y, Futamura T, Hashimoto K. Glutamate Signaling in Synaptogenesis and NMDA Receptors as Potential Therapeutic Targets for Psychiatric Disorders. Curr Mol Med. 2015; 15(3):206-21.

26 Duman RS, Li N. A neurotrophic hypothesis of depression: role of synaptogenesis in the actions of NMDA receptor antagonists. Philos Trans R Soc Lond B Biol Sci. 2012 Sep; 367(1601):2475-84.

27 Chuang HC, Huang TN, Hsueh YP. Neuronal excitation upregulates Tbr1, a high-confidence risk gene of autism, mediating Grin $2 b$ expression in the adult brain. Front Cell Neurosci. 2014 Sep;8:280.

28 Chung C, et al. Early Correction of N-MethylD-Aspartate Receptor Function Improves Autistic-Like Social Behaviors in Adult Shank2(-/-) Mice. Biol Psychiatry. 2019 Apr 1;85(7):534-543.

29 Gandal MJ, Anderson RL, Billingslea EN, Carlson GC, Roberts TP, Siegel SJ. Mice with reduced NMDA receptor expression: more consistent with autism than schizophrenia? Genes Brain Behav. 2012 Aug;11(6):740-50.

30 Ghanizadeh A. Targeting of glycine site on NMDA receptor as a possible new strategy for autism treatment. Neurochem Res. 2011 May; 36(5):922-3.

31 Parsley SL, Pilgram SM, Soto F, Giese KP, Edwards FA. Enriching the environment of alphaCaMKIIT286A mutant mice reveals that LTD occurs in memory processing but must be subsequently reversed by LTP. Learn Mem. 2007 Jan; 14(1-2):75-83.

32 Tarabeux J, Kebir O, Gauthier J, Hamdan FF, Xiong L, Piton A, et al.; S2D team. Rare mutations in N-methyl-D-aspartate glutamate receptors in autism spectrum disorders and schizophrenia. Transl Psychiatry. 2011 Nov; 1(11):e55.

33 Vyklicky V, Krausova B, Cerny J, Ladislav M, Smejkalova T, Kysilov B, et al. Surface Expression, Function, and Pharmacology of DiseaseAssociated Mutations in the Membrane Domain of the Human GluN2B Subunit. Front Mol Neurosci. 2018 Apr;11:110. 
34 Ding JD, Kennedy MB, Weinberg RJ. Subcellular organization of camkii in rat hippocampal pyramidal neurons. J Comp Neurol. 2013 Oct;521(15):3570-83.

35 Goodell DJ, Zaegel V, Coultrap SJ, Hell JW, Bayer KU. DAPK1 Mediates LTD by Making CaMKII/GluN2B Binding LTP Specific. Cell Rep. 2017 Jun;19(11):2231-43.

36 Jalan-Sakrikar N, Bartlett RK, Baucum AJ 2nd, Colbran RJ. Substrate-selective and calcium-independent activation of CaMKII by a-actinin. J Biol Chem. 2012 May;287(19): 15275-83.

37 Johnston HM, Morris BJ. N-methyl-D-aspartate and nitric oxide regulate the expression of calcium/calmodulin-dependent kinase II in the hippocampal dentate gyrus. Brain Res Mol Brain Res. 1995 Jul;31(1-2):141-50.

38 Lai KO, Ip NY. Structural plasticity of dendritic spines: the underlying mechanisms and its dysregulation in brain disorders. Biochim Biophys Acta. 2013 Dec;1832(12):2257-63.

39 Mao LM, Jin DZ, Xue B, Chu XP, Wang JQ. Phosphorylation and regulation of glutamate receptors by CaMKII. Sheng Li Xue Bao. 2014 Jun;66(3):365-72.

40 Allen D, Bond CT, Luján R, Ballesteros-Merino C, Lin MT, Wang K, et al. The SK2-long isoform directs synaptic localization and function of SK2-containing channels. Nat Neurosci. 2011 Jun;14(6):744-9.

41 Ballesteros-Merino C, Watanabe M, Shigemoto R, Fukazawa Y, Adelman JP, Luján R. Differential subcellular localization of SK3containing channels in the hippocampus. Eur J Neurosci. 2014 Mar;39(6):883-92.

42 Hammond RS, Bond CT, Strassmaier T, NgoAnh TJ, Adelman JP, Maylie J, et al. Smallconductance $\mathrm{Ca} 2+$-activated $\mathrm{K}+$ channel type 2 (SK2) modulates hippocampal learning, memory, and synaptic plasticity. J Neurosci. 2006 Feb;26(6): 1844-53.

43 Lin MT, Luján R, Watanabe M, Adelman JP, Maylie J. SK2 channel plasticity contributes to LTP at Schaffer collateral-CA1 synapses. Nat Neurosci. 2008 Feb;11(2):170-7.

44 Ngo-Anh TJ, Bloodgood BL, Lin M, Sabatini BL, Maylie J, Adelman JP. SK channels and NMDA receptors form a Ca2+-mediated feedback loop in dendritic spines. Nat Neurosci. 2005 May;8(5):642-9.

45 Oh MM, Simkin D, Disterhoft JF. Intrinsic Hippocampal Excitability Changes of Opposite Signs and Different Origins in CA1 and CA3 Pyramidal Neurons Underlie Aging-Related Cognitive Deficits. Front Syst Neurosci. 2016 Jun; 10:52.

46 Ohtsuki G, Hansel C. Synaptic Potential and Plasticity of an SK2 Channel Gate Regulate Spike Burst Activity in Cerebellar Purkinje Cells. iScience. 2018 Mar;1:49-54.

47 Stackman RW, Hammond RS, Linardatos E, Gerlach A, Maylie J, Adelman JP, et al. Small conductance $\mathrm{Ca} 2+$-activated $\mathrm{K}+$ channels modulate synaptic plasticity and memory encoding. J Neurosci. 2002 Dec;22(23):1016371.
48 Tonini R, Ferraro T, Sampedro-Castañeda M, Cavaccini A, Stocker M, Richards CD, et al. Small-conductance Ca2+-activated $\mathrm{K}+$ channels modulate action potential-induced $\mathrm{Ca} 2+$ transients in hippocampal neurons. J Neurophysiol. 2013 Mar;109(6):1514-24.

49 Trimmer JS. Subcellular localization of K+ channels in mammalian brain neurons: remarkable precision in the midst of extraordinary complexity. Neuron. 2015 Jan;85(2): 238-56.

50 Maylie J, Bond CT, Herson PS, Lee WS, Adelman JP. Small conductance Ca2+-activated $\mathrm{K}+$ channels and calmodulin. J Physiol. 2004 Jan;554(Pt 2):255-61.

51 McKinon, L.a., Structure of Human (SK2).

52 Prescott SA, Sejnowski TJ. Spike-rate coding and spike-time coding are affected oppositely by different adaptation mechanisms. JNeurosci. 2008 Dec;28(50):13649-61.

53 Sah P, Bekkers JM. Apical Dendritic Location of Slow Afterhyperpolarization Current in Hippocampal Pyramidal Neurons: Implications for the Integration of Long-Term Potentiation. J Neurosci. 1996 Aug;16(15):4537-42.

54 Toporikova N, Chacron MJ. SK channels gate information processing in vivo by regulating an intrinsic bursting mechanism seen in vitro. J Neurophysiol. 2009 Oct;102(4):2273-87.

55 Fakira AK, Portugal GS, Carusillo B, Melyan Z, Morón JA. Increased small conductance calcium-activated potassium type 2 channelmediated negative feedback on N-methyl-Daspartate receptors impairs synaptic plasticity following context-dependent sensitization to morphine. Biol Psychiatry. 2014 Jan;75(2): 105-14.

56 Kuiper EF, Nelemans A, Luiten P, Nijholt I, Dolga A, Eisel U. K(Ca)2 and k(ca) 3 channels in learning and memory processes, and neurodegeneration. Front Pharmacol. 2012 Jun; 3:107.

57 Lee WS, Ngo-Anh TJ, Bruening-Wright A, Maylie J, Adelman JP. Small conductance Ca2+-activated $\mathrm{K}+$ channels and calmodulin: cell surface expression and gating. J Biol Chem. 2003 Jul;278(28):25940-6.

58 Nam YW, Baskoylu SN, Gazgalis D, Orfali R, Cui M, Hart AC, et al. A V-to-F substitution in SK2 channels causes Ca2+ hypersensitivity and improves locomotion in a C. elegans ALS model. Sci Rep. 2018 Jul;8(1):10749.

59 Nam YW, Orfali R, Liu T, Yu K, Cui M, Wul$\mathrm{ff} \mathrm{H}$, et al. Structural insights into the potency of SK channel positive modulators. Sci Rep. 2017 Dec;7(1):17178.

60 Moon HY. N-methyl D-aspartate receptor synaptonuclear signaling and neuronal migration factor (Nsmf) plays a novel role in myoblast proliferation. In Vitro Cell Dev Biol Anim. 2015 Jan;51(1):79-84.

61 Hirai K, Yoshioka H, Kihara M, Hasegawa K, Sakamoto T, Sawada T, et al. Inhibiting neuronal migration by blocking NMDA receptors in the embryonic rat cerebral cortex: a tissue culture study. Brain Res Dev Brain Res. 1999 Apr;114(1):63-7.
62 Rakic P, Komuro H. The role of receptor/ channel activity in neuronal cell migration. J Neurobiol. 1995 Mar;26(3):299-315.

63 Komuro H, Rakic P. Modulation of neuronal migration by NMDA receptors. Science. 1993 Apr;260(5104):95-7.

64 Reiprich P, Kilb W, Luhmann HJ. Neonatal NMDA receptor blockade disturbs neuronal migration in rat somatosensory cortex in vivo. Cereb Cortex. 2005 Mar;15(3):349-58.

65 Lasser M, Tiber J, Lowery LA. The Role of the Microtubule Cytoskeleton in Neurodevelopmental Disorders. Front Cell Neurosci. 2018 Jun;12:165.

66 Hori K, Hoshino M. Neuronal Migration and AUTS2 Syndrome. Brain Sci. 2017 May; 7(5):E54.

67 Hanamura K. Drebrin in Neuronal Migration and Axonal Growth. Adv Exp Med Biol. 2017; 1006:141-55.

$68 \mathrm{Wu}$ Q, Liu J, Fang A, Li R, Bai Y, Kriegstein $\mathrm{AR}$, et al. The dynamics of neuronal migration. Adv Exp Med Biol. 2014;800:25-36.

69 Chang JB, Chen F, Yoon YG, Jung EE, Babcock H, Kang JS, et al. Iterative expansion microscopy. Nat Methods. 2017 Jun;14(6):5939.

70 Tillberg PW, Chen F, Piatkevich KD, Zhao Y, $\mathrm{Yu}$ CC, English BP, et al. Protein-retention expansion microscopy of cells and tissues labeled using standard fluorescent proteins and antibodies. Nat Biotechnol. 2016 Sep;34(9): 987-92.

71 Bedogni F, Hodge RD, Elsen GE, Nelson BR, Daza RA, Beyer RP, et al. Tbr1 regulates regional and laminar identity of postmitotic neurons in developing neocortex. Proc Natl Acad Sci USA. 2010 Jul;107(29):13129-34.

72 Belger A, Carpenter KL, Yucel GH, Cleary KM, Donkers FC. The neural circuitry of autism. Neurotox Res. 2011 Oct;20(3):201-14.

73 Hevner RF, Shi L, Justice N, Hsueh Y, Sheng $\mathrm{M}$, Smiga $\mathrm{S}$, et al. Tbr1 regulates differentiation of the preplate and layer 6. Neuron. 2001 Feb;29(2):353-66.

74 Huang TN, Hsueh YP. Brain-specific transcriptional regulator T-brain-1 controls brain wiring and neuronal activity in autism spectrum disorders. Front Neurosci. 2015 Nov;9: 406

75 Shafritz KM, Dichter GS, Baranek GT, Belger A. The neural circuitry mediating shifts in behavioral response and cognitive set in autism. Biol Psychiatry. 2008 May;63(10):974-80.

76 Penzes P, Cahill ME, Jones KA, VanLeeuwen JE, Woolfrey KM. Dendritic spine pathology in neuropsychiatric disorders. Nat Neurosci. 2011 Mar;14(3):285-93.

77 Phillips M, Pozzo-Miller L. Dendritic spine dysgenesis in autism related disorders. Neurosci Lett. 2015 Aug;601:30-40.

78 Hacohen Y, Wright S, Gadian J, Vincent A, Lim M, Wassmer E, et al. N-methyl-d-aspartate (NMDA) receptor antibodies encephalitis mimicking an autistic regression. Dev Med Child Neurol. 2016 Oct;58(10):1092-4. 
79 Allen D, Fakler B, Maylie J, Adelman JP. Organization and regulation of small conductance $\mathrm{Ca} 2+$-activated $\mathrm{K}+$ channel multiprotein complexes. J Neurosci. 2007 Feb;27(9): 2369-76.

80 Ballesteros-Merino C, Martínez-Hernández J, Aguado C, Watanabe M, Adelman JP, Luján R. Localization of SK2 channels relative to excitatory synaptic sites in the mouse developing Purkinje cells. Front Neuroanat. 2014 Dec;8:154.

81 Ohtsuki G, Piochon C, Adelman JP, Hansel C. SK2 channel modulation contributes to compartment-specific dendritic plasticity in cerebellar Purkinje cells. Neuron. 2012 Jul;75(1): $108-20$.
82 Hansen AK, Nedergaard S, Andreasen M. Intrinsic $\mathrm{Ca} 2+$-dependent theta oscillations in apical dendrites of hippocampal CA1 pyramidal cells in vitro. J Neurophysiol. 2014 Aug. 112(3):631-43.

83 Hlushchenko I, Koskinen M, Hotulainen P. Dendritic spine actin dynamics in neuronal maturation and synaptic plasticity. Cytoskeleton (Hoboken). 2016 Sep;73(9):435-41.

84 Lemieux M, Labrecque S, Tardif C, LabrieDion É, Lebel É, De Koninck P. Translocation of CaMKII to dendritic microtubules supports the plasticity of local synapses. J Cell Biol. 2012 Sep;198(6):1055-73.

85 Bosch M, Castro J, Saneyoshi T, Matsuno H, Sur M, Hayashi Y. Structural and molecular remodeling of dendritic spine substructures during long-term potentiation. Neuron. 2014 Apr;82(2):444-59.
86 Chazeau A, Giannone G. Organization and dynamics of the actin cytoskeleton during dendritic spine morphological remodeling. Cell Mol Life Sci. 2016 Aug;73(16):3053-73.

87 Forrest MP, Parnell E, Penzes P. Dendritic structural plasticity and neuropsychiatric disease. Nat Rev Neurosci. 2018 Mar;19(4):21534.

88 González Burgos I, Nikonenko I, Korz V. Dendritic spine plasticity and cognition. Neural Plast. 2012;2012:875156.

89 Compagnucci C, Piemonte F, Sferra A, Piermarini E, Bertini E. The cytoskeletal arrangements necessary to neurogenesis. Oncotarget. 2016 Apr;7(15):19414-29. 